\title{
(2) OPEN ACCESS \\ Risk factors and outcomes of unrecognised endobronchial intubation in major trauma patients
}

\author{
Guido Heyne, ${ }^{1,2}$ Sebastian Ewens, ${ }^{3}$ Holger Kirsten, ${ }^{4}$ Johannes Karl Maria Fakler, ${ }^{5}$ \\ Orkun Özkurtul, ${ }^{5}$ Gunther Hempel 지, ${ }^{1}$ Sebastian Krämer, ${ }^{6}$ Manuel Florian Struck
}

\begin{abstract}
Handling editor Jason E Smith
'Department of Anesthesiology and Intensive Care Medicine, Universitätsklinikum Leipzig, Leipzig, Sachsen, Germany ${ }^{2}$ Department of Anesthesiology, Intensive Care, and Emergency Medicine, BG Klinikum Bergmannstrost Halle, Halle, Sachsen-Anhalt, Germany ${ }^{3}$ Department of Diagnostic and Interventional Radiology, Universitätsklinikum Leipzig, Leipzig, Sachsen, Germany ${ }^{4}$ Institute for Medical Informatics, Statistics and Epidemiology, Universität Leipzig Medizinische Fakultät, Leipzig, Sachsen, Germany ${ }^{5}$ Division of Traumatology, Department of Orthopedics, Traumatology and Plastic Surgery, Universitätsklinikum Leipzig, Leipzig, Sachsen, Germany

${ }^{6}$ Division of Thoracic Surgery, Department of Visceral, Transplant, Thoracic and Vascular Surgery, Universitätsklinikum Leipzig, Leipzig, Sachsen, Germany
\end{abstract}

\section{Correspondence to} Dr Manuel Florian Struck, Department of Anesthesiology and Intensive Care Medicine, Universitätsklinikum Leipzig, Leipzig, Germany;

manuelstruck@web.de

GH and SE contributed equally.

Received 23 June 2021 Accepted 31 July 2021

\section{Check for updates}

(C) Author(s) (or their employer(s)) 2021. Re-use permitted under CC BY-NC. No commercial re-use. See rights and permissions. Published by BMJ.

\section{To cite: Heyne $\mathrm{G}$,}

Ewens $\mathrm{S}$, Kirsten $\mathrm{H}$, et al.

Emerg Med J Epub ahead

of print: [please include Day

Month Year]. doi:10.1136/

emermed-2021-211786

\section{ABSTRACT}

Background Emergency tracheal intubation during major trauma resuscitation may be associated with unrecognised endobronchial intubation. The risk factors and outcomes associated with this issue have not previously been fully defined.

Methods We retrospectively analysed adult patients admitted directly from the scene to the ED of a single level 1 trauma centre, who received either prehospital or ED tracheal intubation prior to initial whole-body CT from January 2008 to December 2019. Our objectives were to describe tube-to-carina distances (TCDs) via CT and to assess the risk factors and outcomes (mortality, length of intensive care unit stay and mechanical ventilation) of patients with endobronchial intubation (TCD $<0 \mathrm{~cm}$ ) using a multivariable model.

Results We included 616 patients and discovered 26 $(4.2 \%)$ cases of endobronchial intubation identified on CT. Factors associated with an increased risk of endobronchial intubations were short body height (OR per $1 \mathrm{~cm}$ increase $0.89 ; 95 \% \mathrm{Cl} 0.84$ to 0.94 ; $\mathrm{p} \leq 0.001)$, a high body mass index (OR 1.14; $95 \% \mathrm{Cl}$ 1.04 to $1.25 ; p=0.005$ ) and ED intubation (OR 3.62; $95 \% \mathrm{Cl} 1.39$ to $8.90 ; p=0.006)$. Eight of 26 cases underwent tube thoracostomy, four of whom had no evidence of underlying chest injury on CT. There was no statistically significant difference in mortality or length of stay although the absolute number of endobronchial intubations was small.

Conclusions Short body height and high body mass index were associated with endobronchial intubation. Before considering tube thoracostomy in intubated major trauma patients suspected of pneumothorax, the possibility of unrecognised endobronchial intubation should be considered.

\section{INTRODUCTION}

Emergency tracheal intubation is an essential procedure for providing airway security, ventilation and oxygenation in major trauma patients who are in immediate respiratory compromise or who require general anaesthesia during trauma resuscitation. ${ }^{1}$ Intubation success rates vary considerably depending on different emergency medical service systems and training levels of providers. ${ }^{12}$ Severe iatrogenic complications of tracheal intubation are unrecognised oesophageal intubation and endobronchial intubation. ${ }^{3-11}$ The potential consequences of unrecognised endobronchial intubation are not as catastrophic as those resulting from unrecognised oesophageal intubation. Nevertheless, unrecognised endobronchial intubation and

\section{Key messages}

What is already known on this subject

- Unrecognised endobronchial intubation and one-lung ventilation cause atelectasis of the unventilated lung, with subsequent hypercapnia and hypoxaemia. This may aggravate already impaired gas exchange in patients suffering from major trauma.

- There is scant previous evidence defining the risk factors and clinical consequences of unrecognised endobronchial intubation.

\section{What this study adds}

- Short body height, a high body mass index, and emergency department intubation were association with unrecognised endobronchial intubation in this single centre cohort of 616 trauma patients.

- In cases where there is asymmetry of breath sounds and thoracostomy may be indicated, endobronchial intubation should be considered and ideally ruled out.

one-lung ventilation cause atelectasis of the unventilated lung with subsequent hypercapnia and hypoxaemia, which may aggravate already impaired gas exchange in emergency patients. ${ }^{12}$ This phenomenon may be particularly relevant in patients with lung contusions, who represent up to one-third of major trauma patients and are at risk of developing acute respiratory distress syndrome. ${ }^{13} 14$ Furthermore, unrecognised endobronchial intubation is a possible risk factor for avoidable needle decompression and tube thoracostomy on the contralateral side of the chest due to misleading absent breathing sounds that mimic pneumothorax. ${ }^{15}$ Despite these potentially severe complications, there is a lack of previous evidence defining risk factors and clinical consequences of unrecognised endobronchial intubation in major trauma patients.

The primary aims of this study were to estimate the incidence of endobronchial intubations in our study cohort and to identify associations and outcomes for endobronchial intubation.

\section{METHODS}

We conducted a single-centre retrospective database review at our trauma centre involving data from acute major trauma patients who underwent prehospital or ED intubation prior to initial wholebody CT. The primary aim was determination of 
the exact tracheal tube-to-carina distance (TCD) in initial emergency CT with a TCD being $<0$ signifying endobronchial intubation from which we derived our target population. Of particular interest were differences in tracheal intubation location and associations of TCD with the performance of tube thoracostomies. According to previously published data, we hypothesised that unrecognised endobronchial intubation would be associated with avoidable tube thoracostomies and be associated with prehospital intubation rather than ED intubation. ${ }^{11}$

\section{Patient enrolment}

The local trauma registry of the University Hospital Leipzig was reviewed for adult patients admitted between January 2008 and December 2019. The inclusion criteria were age $>18$ years, admission directly from the scene of the accident, emergency tracheal intubation in the prehospital setting at the scene of the accident or during management in the ED prior to initial $\mathrm{CT}$, available trauma scores, $\mathrm{PaO}_{2} / \mathrm{FiO}_{2}(\mathrm{p} / \mathrm{f}$ ) values, American Society of Anesthesiologists (ASA) classification and available chest CT data. Patients with supraglottic airway devices, oesophageal tube malposition, pharyngeal tube malposition and missing radiological reconstruction data were excluded. Paediatric patients were not included in this analysis due to different diagnostic approaches and management responsibilities and separate data acquisition. Data were obtained from medical records, the radiological information system and the picture archiving and communication system (MEDOS RIS V.9.3.3008, Nexus MagicWeb V.VA60C_0115, Visage Imaging, PACS: syngo.plaza, Siemens Healthcare).

\section{General management}

Prehospital care of major trauma patients is performed by emergency response physicians until hospital admission. ED activation and management are organised according to the recommendations of the German Society of Trauma Surgery. Initial whole-body CT is routinely performed immediately after clinical assessment, whereas critically unstable patients may be transferred directly to the operating room or may undergo only head CT. In this study, we analysed CT data for tracheal tube positions with regard to radiological findings (chest pathology and tube thoracostomy) and injury characteristics. Tracheal tube positions were classified according to TCD. TCD was measured by one radiologist (author SE) using the RIS/PACS. If the tracheal tube was past the carina in one mainstem bronchus, the distance was counted as a negative value. Further analysis and measurements were performed by a radiologist (author SE), two anaesthetists (authors MFS and GHey) and a thoracic surgeon (author SK). All patients were studied with an interdisciplinary approach and classified after consensus of all researchers. Patients with tube thoracostomy and radiological absence of thoracic injuries and normal gas exchange were classified as potentially avoidable tube thoracostomy.

\section{Statistical analysis}

The data are reported as the mean (SD) for normally distributed data, the median (IQR) for non-normally distributed data and numbers (percentages). Patient characteristics were compared by applying Fisher's exact test and the Mann-Whitney U test or Student's t-test for non-normally and normally distributed variables, respectively. In-depth statistical comparisons were performed using ORs and 95\% CIs in the framework of logistic regression analysis, considering TCDs $\geq 0 \mathrm{~cm}$ and $<0 \mathrm{~cm}$. We descriptively analysed the trauma context and time from tracheal

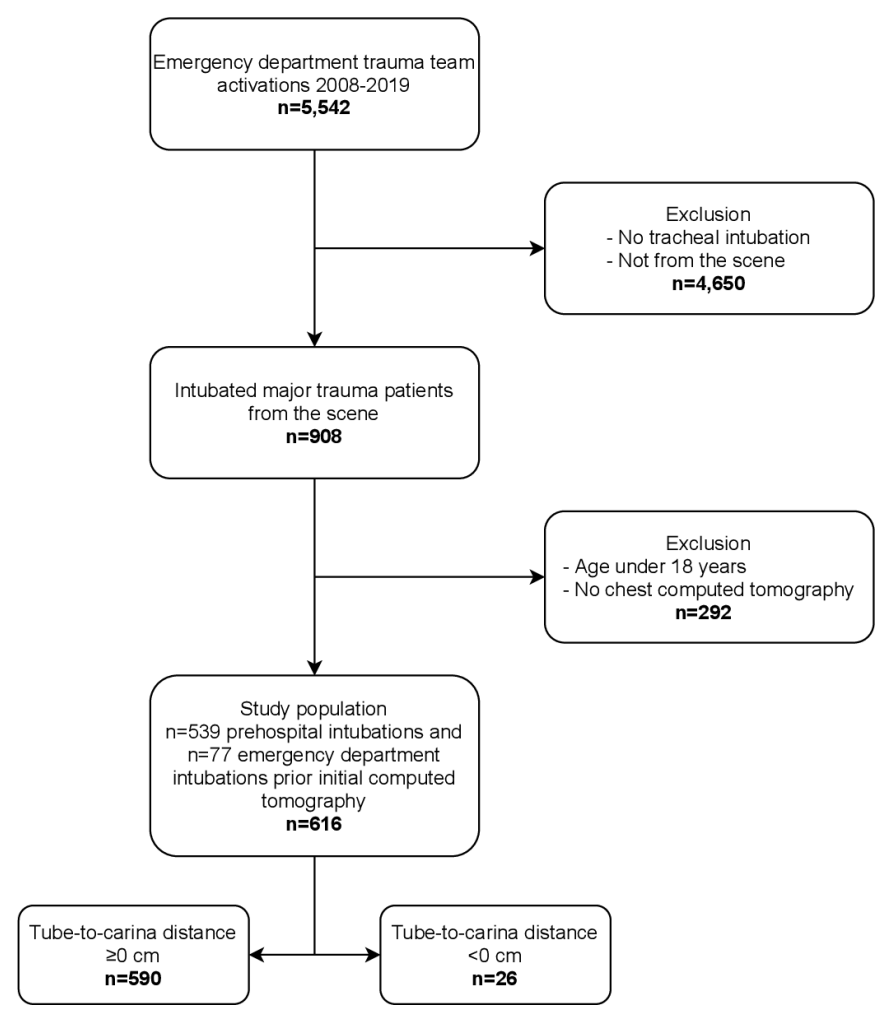

Figure 1 Study flow chart.

intubation until CT diagnostics (reported as the mean \pm SD). The investigated associations for a TCD $<0 \mathrm{~cm}$ were patient characteristics of age; sex; height; weight; body mass index (BMI); Injury Severity Score (ISS); Thoracic Trauma Score, including $\mathrm{CT}$ findings and $\mathrm{p} / \mathrm{f}$ ratios; intubation location; cardiopulmonary resuscitation (CPR) prior to CT; and tube thoracostomy prior to CT. The investigated outcome factors were length of stay in the intensive care unit (ICU), ventilator days, 24-hour mortality, 30-day mortality and hospital mortality. The alpha level of significance was set at 0.05 . All tests were two-tailed. Multivariable analysis was performed on parameters found to be statistically significant in univariable analysis $(p \leq 0.05)$ to assess independent associations. All analyses were performed in the framework of R V.4.0.2.

\section{Patient and public involvement}

Patients or the public were not involved in the design, conduct, reporting or dissemination plans of this study.

\section{RESULTS}

\section{Baseline characteristics}

During the study period, 616 patients were included for further analysis (figure 1). The baseline characteristics for all 616 patients as well as those for the individual groups of patients with a TCD $\geq 0 \mathrm{~cm}$ and a TCD $<0 \mathrm{~cm}$ are displayed in table 1 . Blunt trauma accounted for $97 \%$ of the injuries $(51 \%$ were road traffic accidents, $37 \%$ were falls and $9 \%$ were other blunt trauma mechanisms), and $3 \%$ of the injuries were caused by penetrating trauma.

\section{Tracheal intubation}

Tracheal intubation was performed in the prehospital setting in 539 patients $(87.5 \%)$ and in the ED in 77 patients $(12.5 \%)$ prior to CT diagnostic evaluation. Most tracheal tubes $(n=590$, 
Table 1 Baseline characteristics of the study cohort

\begin{tabular}{|c|c|c|c|c|}
\hline & Overall & $\mathrm{TCD} \geq 0 \mathrm{~cm}$ & $\mathrm{TCD}<0 \mathrm{~cm}$ & $P$ value \\
\hline $\mathrm{N}$ & 616 & 590 & 26 & \\
\hline Age (years) & $50.0[32.0,66.0]$ & $50.0[32.0,65.0]$ & $48.0[32.2,70.8]$ & 0.821 \\
\hline Woman, n (\%) & $168(27.3)$ & $153(25.9)$ & $15(57.7)$ & 0.001 \\
\hline Man, n (\%) & $448(72.7)$ & $437(74.1)$ & $11(42.3)$ & 0.001 \\
\hline Height $(\mathrm{cm})$ & $175.8(8.4)$ & $176.2(8.3)$ & $168.3(6.7)$ & $<0.001$ \\
\hline Weight (kg) & $80.3(13.3)$ & $80.3(13.0)$ & $81.0(18.0)$ & 0.791 \\
\hline BMI & $26.0[24.0,28.0]$ & $25.5[24.0,28.0]$ & $28.5[25.0,30.8]$ & 0.006 \\
\hline ASA I (\%) & $82(13.3)$ & $76(12.9)$ & $6(23.1)$ & 0.267 \\
\hline ASA II (\%) & $386(62.7)$ & $373(63.2)$ & $13(50.0)$ & \\
\hline ASA III (\%) & $134(21.8)$ & $128(21.7)$ & $6(23.1)$ & \\
\hline ASA IV (\%) & $14(2.3)$ & $13(2.2)$ & $1(3.8)$ & \\
\hline ISS & $26.0[20.0,41.0]$ & $27.0[20.0,41.0]$ & $25.0[18.2,36.0]$ & 0.392 \\
\hline TTS & $6.0[3.0,10.0]$ & $6.0[3.0,10.0]$ & $6.0[3.0,10.0]$ & 0.907 \\
\hline $\mathrm{PaO}_{2} / \mathrm{FiO}_{2}$ ratio & $393.0[277.8,439.0]$ & $394.0[282.8,439.0]$ & $385.5[184.0,406.0]$ & 0.163 \\
\hline ETI prehospital, n (\%) & $539(87.5)$ & $522(88.5)$ & $17(65.4)$ & 0.002 \\
\hline ETI ED, n (\%) & 77 (12.5) & $68(11.5)$ & $9(34.6)$ & 0.002 \\
\hline CPR prior $\mathrm{CT}, \mathrm{n}(\%)$ & $78(12.7)$ & $70(11.9)$ & $8(30.8)$ & 0.011 \\
\hline TT prior CT, n (\%) & $142(23.1)$ & $134(22.7)$ & $8(30.8)$ & 0.344 \\
\hline Ventilator (days) & $3.0[0.5,13.2]$ & $3.0[0.5,13.0]$ & $6.0[0.6,18.5]$ & 0.209 \\
\hline ICU (days) & $8.0[2.0,22.0]$ & $8.0[2.0,21.8]$ & $10.5[2.2,25.5]$ & 0.611 \\
\hline 24-hour mortality, n (\%) & $59(9.6)$ & $57(9.7)$ & $2(7.7)$ & 1 \\
\hline 30-day mortality, n (\%) & $147(23.9)$ & $140(23.7)$ & $7(26.9)$ & 0.646 \\
\hline Hospital mortality, n (\%) & $153(24.8)$ & $146(24.7)$ & $7(26.9)$ & 0.817 \\
\hline
\end{tabular}

Squared brackets indicate IQR preceded by medians; round brackets of continuous traits indicate SDs preceded by means.

ASA, American Society of Anesthesiologists; BMI, body mass index; CPR, cardiopulmonary resuscitation; ETI, endotracheal intubation; ICU, intensive care unit; ISS, Injury Severity Score; TCD, tube-to-carina distance; TT, tube thoracostomy; TTS, Thoracic Trauma Score.

95.8\%) were placed above the carina, whereas unrecognised endobronchial intubation (TCD $<0 \mathrm{~cm}$ ) was observed in 26 patients (4.2\%) (figure 2 and table 1). All endobronchial intubations were observed in the right mainstem bronchus. The times between tracheal intubation and CT diagnosis were less than $60 \mathrm{~min}$ in 103 patients (16.7\%), 61-120 $\mathrm{min}$ in 443 patients (71.9\%), 121-180 $\mathrm{min}$ in 59 patients (9.6\%) and more than 180 min in 11 patients $(1.8 \%)$ due to entrapment, difficult resuscitation processes or long referral distances. The mean time was $80.1 \pm 31.2 \mathrm{~min}$ in all patients and $62.8 \pm 21.6 \mathrm{~min}$ in patients with a TCD $<0 \mathrm{~cm}$. Tracheal tube replacement prior to CT diagnostic evaluation was performed in 22 cases due to improper placement (3 cases), clinically detected endobronchial position

Tracheal intubation: $\square$ Prehospital $\square$ Emergency department

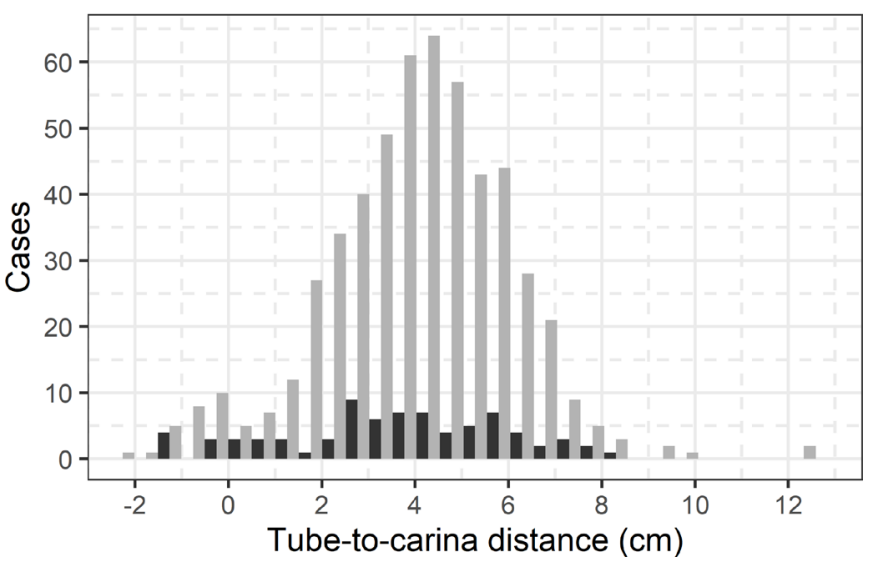

Figure 2 Tube-to-carina distances in CT.
( 3 cases), cuff leakage (2 cases) or unknown reasons (16 cases). Of the 43 cases of tube replacement after CT, 26 presented with endobronchial malposition on CT, 16 had a tube tip position in close proximity to the carina on CT and cuff leakage was recognised in 1 case.

\section{Associations with unrecognised endobronchial intubation}

After adjustment for significant univariable factors, we identified three independent risk factors for a TCD $<0 \mathrm{~cm}$ in our study cohort (table 2).

These three independent risk factors were body height (OR per $1 \mathrm{~cm}$ increase $0.92 ; 95 \%$ CI 0.85 to 0.98 ; $\mathrm{p}=0.016)$, BMI (OR $1.14 ; 95 \%$ CI 1.04 to $1.25 ; \mathrm{p}=0.008$ ) and ED intubation (compared with prehospital intubation; OR 3.91; 95\% CI 1.45 to $10.01 ; \mathrm{p}=0.005)$. The association between a TCD $<0$ and either patient sex or administration of CPR prior to CT did not reach a significant level when adjusting for the other significant predictors (table 2).

Due to low sample sizes (only 26 cases out of 616 patients included), we restricted the five significant variables to the most significant three variables body height, BMI and ED intubation, which confirmed the significance of these variables and resulted in comparable effect size estimators (body height: OR per $1 \mathrm{~cm}$ increase 0.89 ; $95 \%$ CI 0.84 to 0.94 ; $\mathrm{p} \leq 0.001$; BMI: OR 1.14; $95 \%$ CI 1.04 to $1.25 ; \mathrm{p}=0.005$; ED intubation: OR $3.62 ; 95 \%$ CI 1.39 to $8.90 ; \mathrm{p}=0.006$ ) (table 3 ).

\section{Outcomes associated with unrecognised endobronchial intubation}

The outcome factors length of stay in the ICU and mortality were not associated with a TCD $<0 \mathrm{~cm}$. However, power was limited due to the small numbers of cases (table 4). 
Table 2 Associations with unrecognised endobronchial intubation

\begin{tabular}{|c|c|c|c|c|c|c|}
\hline Predictor & Univariable OR $(95 \% \mathrm{Cl})$ & $P$ value & FDR & Multivariable OR $(95 \% \mathrm{Cl})$ & $P$ value & FDR \\
\hline Age & 1.00 (0.98 to 1.02 ) & 0.78 & 0.98 & & & \\
\hline Male gender & 0.26 (0.11 to 0.57 ) & 0.0009 & 0.005 & 0.58 (0.17 to 1.84$)$ & 0.36 & 0.36 \\
\hline Height & 0.89 (0.85 to 0.94$)$ & $<0.0001$ & 0.0002 & 0.92 (0.85 to 0.98$)$ & 0.016 & 0.027 \\
\hline Weight & 1.00 (0.97 to 1.03$)$ & 0.79 & 0.98 & & & \\
\hline BMI & 1.18 (1.08 to 1.28$)$ & 0.0003 & 0.002 & 1.14 (1.04 to 1.25$)$ & 0.008 & 0.02 \\
\hline ASA & 0.88 (0.47 to 1.59$)$ & 0.67 & 0.98 & & & \\
\hline ISS & 0.99 (0.96 to 1.01$)$ & 0.32 & 0.65 & & & \\
\hline TTS & 1.00 (0.92 to 1.07$)$ & 0.42 & 0.98 & & & \\
\hline $\mathrm{PaO}_{2} / \mathrm{FiO}_{2}$ ratio & 1.00 (1.00 to 1.00$)$ & 0.14 & 0.44 & & & \\
\hline ETI ED & 4.06 (1.67 to 9.29$)$ & 0.001 & 0.006 & 3.91 (1.45 to 10.01$)$ & 0.005 & 0.02 \\
\hline CPR prior CT & 3.30 (1.31 to 7.63$)$ & 0.007 & 0.027 & 2.32 (0.84 to 5.87$)$ & 0.087 & 0.11 \\
\hline TT prior CT & 1.51 (0.61 to 3.45$)$ & 0.34 & 0.65 & & & \\
\hline
\end{tabular}

ASA, American Society of Anesthesiologists; BMI, body mass index; CPR, cardiopulmonary resuscitation; ETI, endotracheal intubation; FDR, false discovery rate; ISS, Injury Severity Score; TT, tube thoracostomy; TTS, Thoracic Trauma Score.

\section{Association of tube thoracostomy and unrecognised endobronchial intubation}

One hundred forty-two patients underwent tube thoracostomy prior to CT, of whom eight had a TCD $<0 \mathrm{~cm}$, including seven with contralateral endobronchial intubation. In four of these seven patients, tube thoracostomy was performed only due to absent breathing sounds (according to their charts) and considered to be avoidable according to clinical data and CT findings. The remaining three patients and the patient with ipsilateral tube thoracostomy had severe chest injuries (ie, relevant lung contusions, pneumothorax with subcutaneous emphysema and/or haemothorax, multiple rib fractures and/or sternum fracture and cardiac tamponade). In the 22 patients in which endobronchial intubation was corrected prior to CT, five underwent left-sided tube thoracostomy. Four of these cases of thoracostomy were associated with no observed intrathoracic pathology on CT. In the remaining patients with a TCD $\geq 0 \mathrm{~cm}$, we identified another four with left-sided atelectasis and tube thoracostomy placement without significant chest trauma on CT.

\section{DISCUSSION}

The observed incidence of unrecognised endobronchial intubation of $4.2 \%$ in our study is in line with that in previous studies of radiographic confirmation of tracheal tube position. In the last three decades, various studies have found the incidence of patients with a TCD $<0 \mathrm{~cm}$ to be $1.8 \%-10.7 \% \cdot \cdot^{3-58-10}$ However, studies particularly designed to assess bronchial malposition after emergency intubation in adult major trauma patients are scarce. Available studies included cohorts with relatively low sample sizes and often presented considerable heterogeneity in patient selection (trauma and/or non-trauma emergencies), setting (prehospital and/or ED intubations) and method of radiological measurement (plain chest radiography and/or CT).

Table 3 Adjusted multivariable model of the three most significant variables associated with unrecognised endobronchial intubation

\begin{tabular}{llcr}
\hline Predictor & Adjusted OR $(95 \% \mathrm{Cl})$ & P value & \multicolumn{1}{l}{ FDR } \\
\hline Body height* & $0.89(0.84$ to 0.94$)$ & $<0.001$ & $<0.001$ \\
BMI & $1.14(1.04$ to 1.25$)$ & 0.005 & 0.006 \\
ETI ED & $3.62(1.39$ to 8.90$)$ & 0.006 & 0.006 \\
\hline
\end{tabular}

*Per $1 \mathrm{~cm}$ increase.

BMI, body mass index; ETI, endotracheal intubation; FDR, false discovery rate.;

\section{Associations with endobronchial intubation}

There was a statistically significant association between short body height and high BMI and endobronchial intubation. There was also a statistically significant signal for ED intubation, but the numbers were small, and therefore, this requires further evaluation.

Inadvertent endobronchial malposition in emergency intubation is a known problem that is associated with shorter stature. ${ }^{1516}$ Our results confirm this association. High BMI is a known risk factor for difficult airways in clinical anaesthesia, which might contribute to unrecognised deep tube malposition. ${ }^{17-19}$

Notably, we identified ED intubation as an independent risk factor for unrecognised endobronchial intubation in our study. This is particularly interesting because all providers who performed the tracheal intubations in the ED were experienced consultant anaesthetists. In a previous study, we found that prehospital airway management and ISS were independently associated with mechanical complications. ${ }^{11}$ One possible reason for the contradictory result might have been the considerably smaller sample size of ED intubations compared with prehospital intubations. Another possible reason might have been that prehospital emergency response physicians postponed airway management and intubation to the ED in high-risk patients. ${ }^{20} 21$ For this study, the significance of ED intubation as a risk factor for unrecognised endobronchial intubation remains unclear, and further prospective studies are needed to confirm our findings and to discover possible causes.

Regarding other possible risk variables for a TCD $<0 \mathrm{~cm}$, we assumed that increasing patient movement during chest

Table 4 Outcomes associated with unrecognised endobronchial intubation

\begin{tabular}{lllll}
\hline Predictor & $\begin{array}{l}\text { Outcome (dependent } \\
\text { variable) }\end{array}$ & $\begin{array}{l}\text { Effect size }(95 \% \mathrm{Cl}) \\
\text { (univariable) }\end{array}$ & $\begin{array}{l}\text { P } \\
\text { value }\end{array}$ & FDR \\
\hline $\mathrm{TCD}<0 \mathrm{~cm}$ & ICU days $^{*}$ & $0.15(-0.41$ to 0.72$) \dagger$ & 0.6 & 0.8 \\
$\mathrm{TCD}<0 \mathrm{~cm}$ & Ventilator days* & $0.4(-0.27$ to 1.08$) \dagger$ & 0.24 & 0.8 \\
$\mathrm{TCD}<0 \mathrm{~cm}$ & 24-hour mortality & $0.78(0.12$ to 2.72$) \ddagger$ & 0.74 & 0.8 \\
$\mathrm{TCD}<0 \mathrm{~cm}$ & 30-day mortality & $1.18(0.45$ to 2.76$) \ddagger$ & 0.71 & 0.8 \\
$\mathrm{TCD}<0 \mathrm{~cm}$ & Hospital mortality & $1.12(0.43$ to 2.61$) \ddagger$ & 0.8 & 0.8 \\
\hline
\end{tabular}

*Natural logarithm of outcome used.

tQuantified as OR from logistic regression.

¥Quantified as slope from linear regression.

$F D R$, false discovery rate; ICU, intensive care unit; $T C D$, tube-to-carina distance. 
compressions in CPR and/or tube thoracostomy might have contributed to dislocation of the tracheal tube and thus may have been associated with endobronchial malposition, but neither parameter was an independent predictor.

\section{Outcomes}

Our results suggest that major trauma patients experiencing unrecognised endobronchial intubation are not associated with adverse outcomes compared with patients with correctly placed tubes. Mortality rates were similar in all groups. One reason for the absence of severe complications after unrecognised endobronchial intubation may have been the short time from intubation until detection via CT, which remained under $80 \mathrm{~min}$ in all but one patient. Additionally, the majority of patients with unrecognised endobronchial intubation were generally young and classified as ASA I or II. Furthermore, high levels of $\mathrm{FiO}_{2}$ administration (0.5-1.0) are usually applied in emergency patients, which prevents severe desaturation, even in unrecognised one-lung ventilation. ${ }^{12-14}$

\section{Avoidable tube thoracostomy}

Unrecognised endobronchial intubation carries the risk of invasive consequences when unilateral missing breathing sounds lead to tube thoracostomy out of concern for possible pneumothorax. ${ }^{15}$ We investigated all patients who underwent tube thoracostomy, particularly those with an unrecognised TCD $<0$ $\mathrm{cm}$. Four of seven patients with contralateral tube thoracostomy were suspected of having avoidable thoracostomy according to clinical presentation and CT results. It might have been that the number of avoidable tube thoracostomies was considerably higher. Reliable detection of pneumothorax in the prehospital setting or the ED is not always possible, and pleural decompression is often performed according to auscultation and/or under consideration of underlying chest trauma mechanisms.

For the prevention of deep tube malposition, the recommended insertion depths of tracheal tubes for achieving an acceptable TCD are $20-21 \mathrm{~cm}$ in women and $22-23 \mathrm{~cm}$ in men, although special circumstances (head and neck movements during interventions) and stature (eg, short neck anatomy) always require individual considerations. ${ }^{1622}{ }^{23}$ Although we did not document tube insertion lengths at ED admission in the current study, we recommend its documentation in the charts. Moreover, a standardised assessment including all relevant parameters of emergency airway management is strongly recommended in order to provide comparability in future studies. ${ }^{24}$

\section{Limitations}

We acknowledge the general limitations of retrospective studies. Although we present a study cohort with homogeneous patient selection, one main limitation is the relatively small dataset, so the results are hypothesis generating rather than conclusive, and further studies are needed. We only included patients who underwent CT following tracheal intubation. A considerable number of intubated critical trauma patients who died before CT evaluation, who were too unstable for CT and underwent immediate surgery without CT or who received only head CT might have presented with different risk factors and outcomes. Detailed analysis of airway management was not possible due to inconsistent documentation or missing data.

\section{CONCLUSIONS}

Unrecognised endobronchial intubation is a rare complication that should nevertheless be considered in any emergency tracheal intubation. Independent risk factors in our study were short body height, a high BMI and ED intubation. Given our limited sample size, these findings need to be confirmed in future studies, especially the role of ED intubation. Although unrecognised endobronchial intubation did not affect outcome, it should be considered before tube thoracostomy in intubated major trauma patients suspected of pneumothorax.

Acknowledgements The authors would like to thank all participating colleagues and patients.

Contributors MFS had the idea for the study and supervised the study. SE performed the computed tomography analyses. MFS and GHey collected and analysed the data. HK led the statistical data analysis. JKMF, OÖ, GHem and SK were involved in the analysis of the data. All authors were involved in the writing of the manuscript.

Funding The authors have not declared a specific grant for this research from any funding agency in the public, commercial or not-for-profit sectors.

Competing interests None declared.

Patient and public involvement Patients and/or the public were not involved in the design, conduct, reporting or dissemination plans of this research.

Patient consent for publication Not required.

Ethics approval Ethical approval was obtained from the ethics committee of the Medical Faculty of Leipzig, Germany (No. 441/15-ek, 14 September 2020).

Provenance and peer review Not commissioned; externally peer reviewed.

Data availability statement Data are available upon reasonable request.

Open access This is an open access article distributed in accordance with the Creative Commons Attribution Non Commercial (CC BY-NC 4.0) license, which permits others to distribute, remix, adapt, build upon this work non-commercially, and license their derivative works on different terms, provided the original work is properly cited, appropriate credit is given, any changes made indicated, and the use is non-commercial. See: http://creativecommons.org/licenses/by-nc/4.0/.

\section{ORCID iDs}

Gunther Hempel http://orcid.org/0000-0002-9705-5184

Manuel Florian Struck http://orcid.org/0000-0002-0070-3406

\section{REFERENCES}

1 Crewdson K, Rehn M, Lockey D. Airway management in pre-hospital critical care: a review of the evidence for a 'top five' research priority. Scand J Trauma Resusc Emerg Med 2018;26:89.

2 Fouche PF, Stein C, Simpson P, et al. Nonphysician Out-of-Hospital Rapid Sequence Intubation Success and Adverse Events: A Systematic Review and Meta-Analysis. Ann Emerg Med 2017;70:449-59.

3 Bissinger $\mathrm{U}$, Lenz G, Kuhn W. Unrecognized endobronchial intubation of emergency patients. Ann Emerg Med 1989:18:853-5.

4 Jemmett ME, Kendal KM, Fourre MW, et al. Unrecognized misplacement of endotracheal tubes in a mixed urban to rural emergency medical services setting. Acad Emerg Med 2003;10:961-5.

5 Timmermann A, Russo SG, Eich C, et al. The out-of-hospital esophageal and endobronchial intubations performed by emergency physicians. Anesth Analg 2007;104:619-23.

6 Wirtz DD, Ortiz C, Newman DH, et al. Unrecognized misplacement of endotracheal tubes by ground prehospital providers. Prehosp Emerg Care 2007;11:213-8.

7 Cobas MA, De la Peña MA, Manning R, et al. Prehospital intubations and mortality: a level 1 trauma center perspective. Anesth Analg 2009;109:489-93.

8 Geisser W, Maybauer DM, Wolff H, et al. Radiological validation of tracheal tube insertion depth in out-of-hospital and in-hospital emergency patients. Anaesthesia 2009;64:973-7.

9 Hossein-Nejad H, Payandemehr P, Bashiri SA, et al. Chest radiography after endotracheal tube placement: is it necessary or not? Am J Emerg Med 2013:31:1181-2.

10 Ono Y, Kakamu T, Kikuchi H, et al. Expert-Performed endotracheal IntubationRelated complications in trauma patients: incidence, possible risk factors, and outcomes in the prehospital setting and emergency department. Emerg Med Int 2018:2018:1-9.

11 Struck MF, Fakler JKM, Bernhard M, et al. Mechanical complications and outcomes following invasive emergency procedures in severely injured trauma patients. Sci Rep 2018;8:3976.

12 Lohser J, Slinger P. Lung injury after one-lung ventilation: a review of the pathophysiologic mechanisms affecting the ventilated and the collapsed lung. Anesth Analg 2015;121:302-18. 


\section{Original research}

13 Schulz-Drost $S$, Finkbeiner R, Lefering $R$, et al. Lung contusion in Polytrauma: an analysis of the TraumaRegister DGU. Thorac Cardiovasc Surg. doi:10.1055/s-0039-1700505. [Epub ahead of print: 13 Dec 2019].

14 Birkner DR, Halvachizadeh S, Pape H-C, et al. Mortality of adult respiratory distress syndrome in trauma patients: a systematic review over a period of four decades. World J Surg 2020;44:2243-54.

15 Simons T, Söderlund T, Handolin L. Radiological evaluation of tube depth and complications of prehospital endotracheal intubation in pediatric trauma: a descriptive study. Eur J Trauma Emerg Surg 2017;43:797-804.

16 Herway ST, Benumof JL. The tracheal accordion and the position of the endotracheal tube. Anaesth Intensive Care 2017:45:177-88.

17 Holmberg TJ, Bowman SM, Warner KJ, et al. The association between obesity and difficult prehospital tracheal intubation. Anesth Analg 2011;112:1132-8.

18 Wang T, Sun S, Huang S. The association of body mass index with difficult tracheal intubation management by direct laryngoscopy: a meta-analysis. BMC Anesthesiol 2018;18:79.

19 Yakushiji H, Goto T, Shirasaka W, et al. Associations of obesity with tracheal intubation success on first attempt and adverse events in the emergency department: an analysis of the multicenter prospective observational study in Japan. PLoS One 2018;13:e0195938.

20 Fevang E, Perkins Z, Lockey D, et al. A systematic review and meta-analysis comparing mortality in pre-hospital tracheal intubation to emergency department intubation in trauma patients. Crit Care 2017;21:192.

21 Schwaiger P, Schöchl H, Oberladstätter D, et al. Postponing intubation in spontaneously breathing major trauma patients upon emergency room admission does not impair outcome. Scand J Trauma Resusc Emerg Med 2019;27:80.

22 Roberts JR, Spadafora M, Cone DC. Proper depth placement of oral endotracheal tubes in adults prior to radiographic confirmation. Acad Emerg Med 1995;2:20-4.

23 Sitzwohl C, Langheinrich A, Schober A, et al. Endobronchial intubation detected by insertion depth of endotracheal tube, bilateral auscultation, or observation of chest movements: randomised trial. BMJ 2010;341:c5943.

24 Sunde GA, Kottmann A, Heltne JK, et al. Standardised data reporting from prehospital advanced airway management - a nominal group technique update of the Utstein-style airway template. Scand J Trauma Resusc Emerg Med 2018;26:46. 